\title{
Article
}

\section{The Correlation between Oral Self-Harm and Ethnicity in Institutionalized Children}

\author{
Alexandra Mihaela Stoica ${ }^{1}$, Oana Elena Stoica ${ }^{2}$, Ramona Elena Vlad ${ }^{1}$, Anca Maria Pop ${ }^{3, *}$ and Monica Monea ${ }^{1}$ \\ 1 Department of Odontology and Oral Pathology, George Emil Palade University of Medicine, Pharmacy, \\ Science, and Technology of Târgu Mureș, 540139 Târgu Mureș, Romania; alexandra.stoica@umfst.ro (A.M.S.); \\ ramona.vlad@umfst.ro (R.E.V.); monica.monea@umfst.ro (M.M.) \\ 2 Department of Pedodontics, George Emil Palade University of Medicine, Pharmacy, Science, and Technology \\ of Târgu Mures, 540139 Târgu Mures, Romania; oana.stoica@umfst.ro \\ 3 Faculty of Medicine, George Emil Palade University of Medicine, Pharmacy, Science, and Technology of \\ Târgu Mureș, 540139 Târgu Mureș, Romania \\ * Correspondence: ancapop98@yahoo.com
}

check for

updates

Citation: Stoica, A.M.; Stoica, O.E.; Vlad, R.E.; Pop, A.M.; Monea, M. The Correlation between Oral Self-Harm and Ethnicity in Institutionalized Children. Children 2021, 8, 2. https://dx. doi.org/10.3390/children8010002

Received: 15 November 2020 Accepted: 21 December 2020 Published: 23 December 2020

Publisher's Note: MDPI stays neutral with regard to jurisdictional claims in published maps and institutional affiliations.

Copyright: () 2020 by the authors. Licensee MDPI, Basel, Switzerland. This article is an open access article distributed under the terms and conditions of the Creative Commons Attribution (CC BY) license (https: / / creativecommons.org/ licenses/by/4.0/).

\begin{abstract}
Oral self-harm was described in institutionalized children who share a lack of emotional attention; frequently these children experience feelings such as neglect, loneliness, isolation or lack of connection with the world. The aim of our paper was to conduct a cross-sectional study in order to assess the prevalence of this behavior and its correlation with ethnicity among children from three institutions located in the central part of Romania. We examined 116 children from three ethnic groups, Romanians, Hungarians and local Roma population aged between 10-14 years old. The oral soft tissues were evaluated by one dentist who recorded the lesions of lips, buccal mucosa, commissures and tongue; data were statistically analyzed at a level of significance of $p<0.05$. We found oral self-harm lesions in $18.1 \%$ participants, with statistically significant higher odds in girls $(p=0.03)$. The results showed an association between ethnicity and the development of these lesions (Chi-square $p=0.04)$. The most frequent lesions were located at oral commissures $(35.48 \%)$, buccal mucosa (29.03\%) and upper lip (19.36\%). Oral self-harm lesions have a high incidence among institutionalized children in Romania. Identification of these cases in early stages is important, as these conditions are known to be aggravated during adolescence and adulthood.
\end{abstract}

Keywords: self-injurious behavior; institutionalized child; oral manifestations

\section{Introduction}

Self-mutilation is defined as a behavioral disturbance that consists of self-induced damage to body tissues, which might be associated in some cases with a conscious intent to commit suicide. Also called self-harm, it includes any intentional injury to one's own body [1-4]. Historically, the first institutions for abandoned children can be traced back in Europe since the Middle Ages; they came into prominence in the 19th century in Western Europe, today being common in different parts of the world such as Asia, Central and South America, the Middle East or Africa. In the United States, orphanages were documented in the first half of the 20th century [5].

At present, worldwide there are between 8-10 million children living in different types of institution [6] and there is much scientific evidence that their psychological development is impaired by these life conditions [7]; furthermore, the trend of placing children in institutions appears to be growing [8,9]. According to data from literature, institutional care in Romania was associated with an impairment of the physical development [10] and also children who spent more than 6 months in an institution had higher rates of autism symptoms, inattention or disinhibited social engagement [11]. Due to the demands of taking care of a large number of children, the caregivers rarely interact with children in a warm manner, as their activity is frequently limited to routine care, such as feeding or 
toileting [12]. Therefore, most institutionalized children experience poor caregiver-child interaction and their physical, cognitive and social development is often delayed. Moreover, scientific data showed that these results are caused mainly by the quality of caregiver-child relationships, rather than by the quality of medical care and nutrition [13]. The inability to live with their parents predisposes institutionalized children to low self-esteem and impaired psychosocial development (attention problems or lower intelligence quotient) [7], which might represent confounding factors in the analysis of the correlation between self-harm and institutionalization.

In institutionalized children, the relief of emotional pain could be expressed by selfharm, as the physical wounds they create on themselves is a sign of their emotional suffering [14]. The self-harm behavior has many causes, including stressful life events or mental disorders such as depression or anxiety [15]. Adolescents use deliberate self-harm methods such as cutting, poisoning or overdosing, while children usually scratch or bite themselves; this phenomenon may start during childhood and intensifies in adolescents and young adults, girls being considered more vulnerable to this behavior than boys [16]. Among the etiological factors of deliberate self-harm the following conditions were included: depression, low self-esteem and sense of persistent hopelessness, attempts to seek help from others, poverty, abuse, attempts to resist suicidal thoughts and family dysfunction. The early detection of non-suicidal self-injury (NSSI) allows immediate intervention which might help these children stop this behavior. Left undiagnosed for a long period of time, NSSI becomes more frequent, severe and versatile, with negative consequences on the quality of life and more difficult recovery [17].

Oral self-harm $(\mathrm{OSH})$ in institutionalized children occurs in connection with emotional, behavioral or even organic disorders. To date, most of the information comes from case series presentations and there are little scientific data regarding the frequency of $\mathrm{OSH}$ among abandoned children without mental disorders or retardation. Therefore, the aim of our paper was to conduct a cross-sectional study in order to assess the frequency and type of OSH among institutionalized children from three Romanian state centers. The null hypothesis to be tested was that there is no statistically significant difference regarding the prevalence of oral self-inflicted lesions, according to gender and ethnicity in children at puberty.

\section{Materials and Methods}

\subsection{Study Design and Participants}

Our investigation was conducted between December 2019-February 2020 in the Clinic of Odontology and Oral Pathology from the George Emil Palade University of Medicine, Pharmacy, Science, and Technology of Târgu Mureș, where there is a special program dedicated to dental medical care for institutionalized children, belonging to three state centers. The investigation was carried out after the approval obtained from the Ethics Committee of our university (No. 520/21.11.2019), accompanied by a written consent for the use of personal data signed in each case by the legal representative of the child (institution manager or legal guardian). Prior to enrolment in the study, children were also asked if they agreed to participate. We are located in the historical province of Transylvania, characterized by a multicultural and multiethnic population, represented mainly by Romanians, Hungarians and regional Roma. In order to address a source of bias related to the number of participants from each ethnicity, we decided to include close numbers in each group, according to age and gender. Moreover, all clinical examinations were carried out by one experienced dentist and data were recorded by one dental specialist. In our study we included 116 children aged between 10-14 years old, selected from a total of 167 children, based on application of inclusion criteria (status of institutionalized child for more than 5 years, age 10-14 years) and exclusion criteria (history of psychological counseling or psychiatric treatment, recordings of drugs or alcohol abuse, children with diagnosed neurologic or psychiatric disorders, known to be etiological factors of self-harm behavior, such as epilepsy, depression, anxiety or autism spectrum disorder) (Figure 1). 
167 children aged $10-14$ assessed for

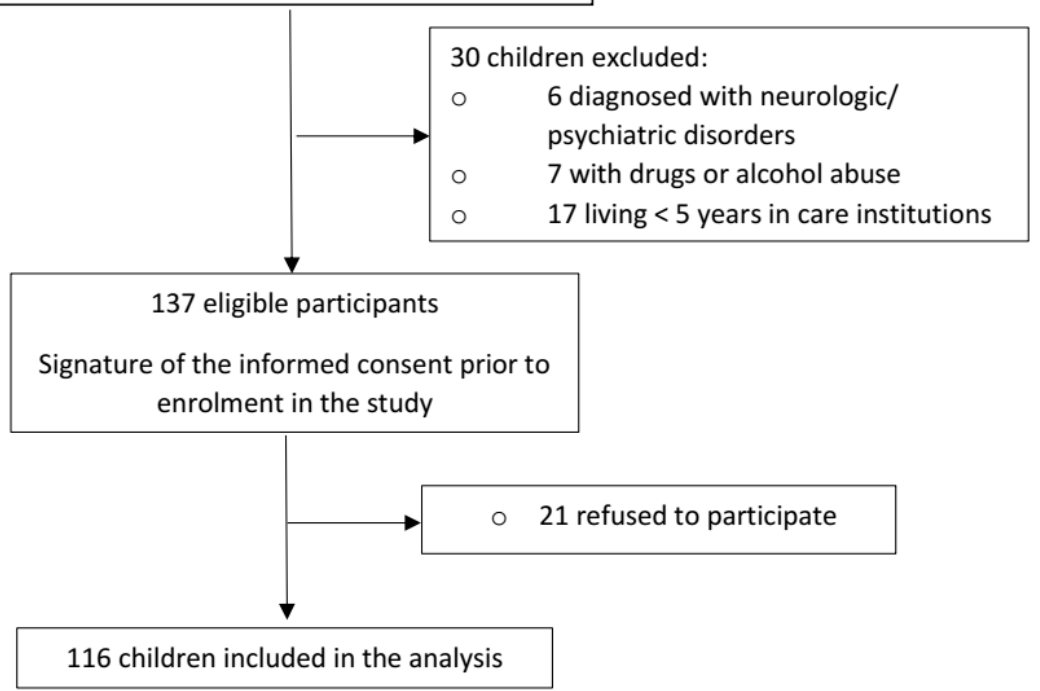

Figure 1. Flow diagram illustrating selection of participants to the study.

\subsection{Clinical and Histopathological Examination}

Ordinary dental examinations, with an emphasis on the health status of the lips, buccal mucosa and tongue (ulcerations, color change, surface aspect), were performed. In order to detect any changes from normal texture, the area between oral commissures was carefully evaluated by palpation. Cases in which a chronic evolution was suspected, resembling premalignant lesions, were further investigated by exfoliative cytology, using Papanicolau stain. All children who presented OSH were further referred to interdisciplinary evaluation by a psychologist and dental specialist.

\subsection{Statistical Analysis}

Statistical analysis was carried out using GraphPad Prism 7 for Windows (GraphPad Software, San Diego, CA, USA), by Fisher's exact test and Chi-square test. The continuous variables were expressed as mean \pm standard deviation and categorical variables as percentages and frequency distribution. The level of statistical significance was set at a $p$ value $<0.05$ (two-tailed).

\section{Results}

The distribution of the study group based on gender and ethnicity is presented in Table 1.

Table 1. Distribution of the study group according to gender and ethnicity.

\begin{tabular}{ccccc}
\hline Gender/Ethnicity & Romanians & Hungarians & Roma & Total \\
\hline Female & $20(17.24 \%)$ & $19(16.38 \%)$ & $24(20.69 \%)$ & $63(54.31 \%)$ \\
\hline Male & $17(14.65 \%)$ & $15(12.93 \%)$ & $21(18.11 \%)$ & $53(45.69 \%)$ \\
\hline Total & $37(31.89 \%)$ & $34(29.31 \%)$ & $45(38.8 \%)$ & $116(100 \%)$ \\
\hline
\end{tabular}

The mean age of the study group was $12.11 \pm 1.36$ years.

The presence of OSH was noticed in 21 participants (18.1\%). According to Fisher's exact test, girls had statistically significant higher odds of presenting OSH than boys (odds ratio $(\mathrm{OR})=3.268,95 \%$ confidence interval $(\mathrm{CI}): 1.108-9.643, p=0.03$ ) (Table 2). 
Table 2. The distribution of lesions according to gender.

\begin{tabular}{cccc}
\hline Gender/Oral Lesion & Oral Lesion Present & Oral Lesion Absent & Total \\
\hline Female & $16(13.79 \%)$ & $47(40.52 \%)$ & $63(54.31 \%)$ \\
\hline Male & $5(4.31 \%)$ & $48(41.38 \%)$ & $53(45.69 \%)$ \\
\hline Total & $21(18.1 \%)$ & $95(81.9 \%)$ & $116(100 \%)$ \\
\hline
\end{tabular}

The results of our study showed that the presence of self-inflicted oral lesions is influenced by ethnicity (Chi-square original $p=0.04$ ). After applying the Bonferroni correction, the level of statistical significance was adjusted at $p<0.0167$. Therefore, Romanians had statistically significant lower odds of developing oral self-injuries compared to Roma participants (OR $=0.15,95 \%$ CI: $0.03-0.75, p=0.0164)$, but there was no significant difference neither between Romanians and Hungarians ( $\mathrm{OR}=0.22,95 \% \mathrm{CI}: 0.04-1.148, p=0.07$ ), nor between Hungarians and Roma participants (OR $=0.71,95 \%$ CI: $0.24-2.06, p=0.6$ ) (Table 3).

Table 3. The distribution of oral lesions according to ethnicity.

\begin{tabular}{cccc}
\hline Ethnicity/Oral Lesion & Oral Lesion Present & Oral Lesion Absent & Total \\
\hline Romanian & $2(1.72 \%)$ & $35(30.17 \%)$ & $37(31.89 \%)$ \\
\hline Hungarian & $7(6.03 \%)$ & $27(23.28 \%)$ & $34(29.31 \%)$ \\
\hline Roma & $12(10.35 \%)$ & $33(28.45 \%)$ & $45(38.8 \%)$ \\
\hline Total & $21(18.1 \%)$ & $95(81.9 \%)$ & $116(100 \%)$ \\
\hline
\end{tabular}

In Table 4 the types of encountered lesions are summarized, based on location and frequency.

Table 4. Frequency of oral self-inflicted lesions according to location.

\begin{tabular}{ccc}
\hline Location of Lesion & Number & Frequency \\
\hline Upper lip & 6 & $19.36 \%$ \\
\hline Lower lip & 4 & $12.90 \%$ \\
\hline Tongue & 1 & $3.23 \%$ \\
\hline Buccal mucosa & 9 & $29.03 \%$ \\
\hline Commissures & 11 & $35.48 \%$ \\
\hline
\end{tabular}

Most lesions were observed at the level of oral commissures (35.48\%), followed by buccal mucosa (29.03\%) and the upper lip (19.36\%). The lowest value was obtained for the frequency of tongue lesions (3.23\%). Suggestive clinical and histopathological aspects are presented in Figures 2 and $3 a, b$. 


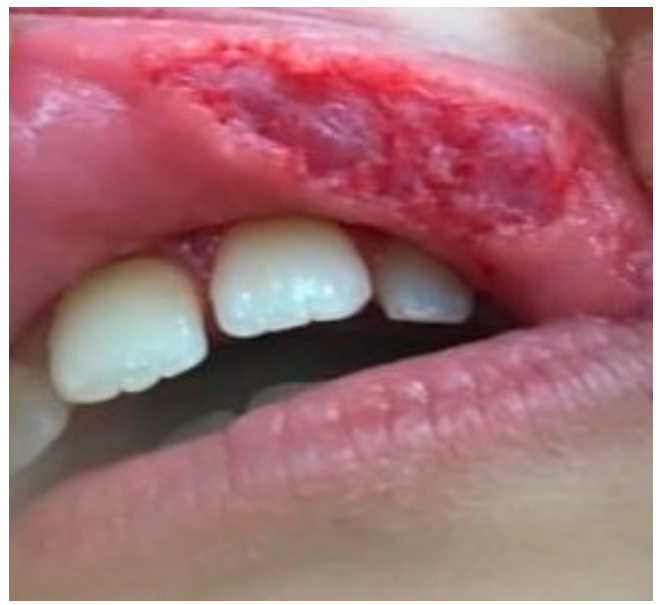

Figure 2. 14-year-old female patient, with a large wound on her upper lip, non-bleeding area of $1 \times 2 \mathrm{~cm}$ on the non-keratinized mucosa, surrounded by erythema that did not involve the vermilion border.
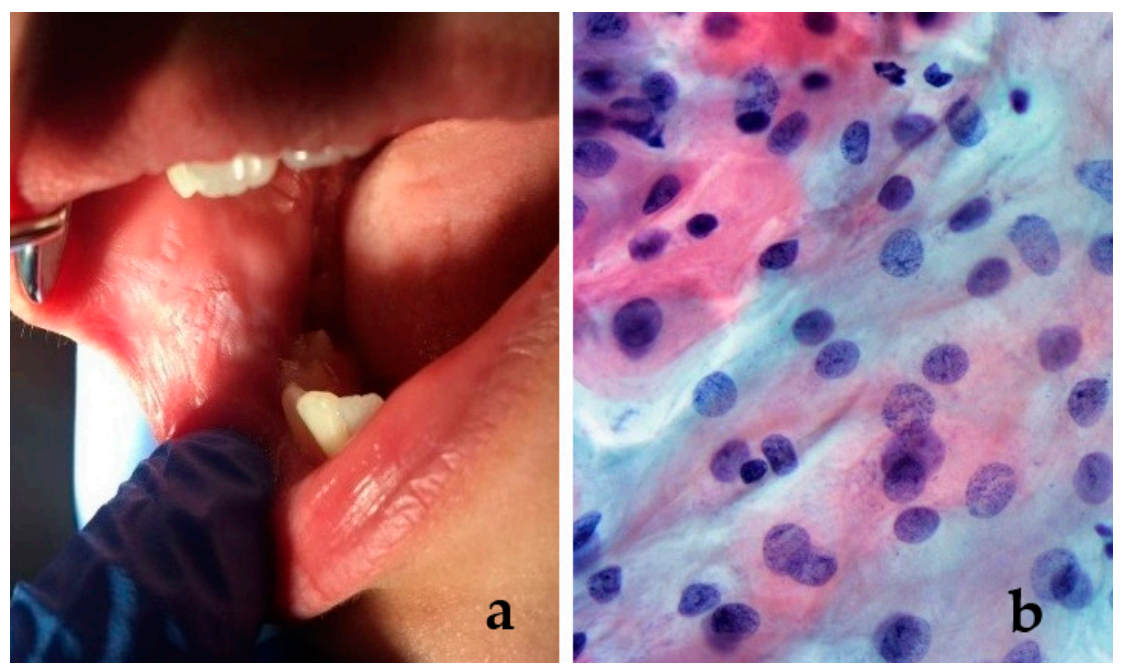

Figure 3. (a) A 12-year-old female patient with a white "patch" on the buccal mucosa, resembling leukoplakia; histopathological examination was performed in order to obtain the correct diagnosis; (b) exfoliative cytology did not confirm the presence of a premalignant lesion. Intermediate squamous cells (reflecting the accelerate turnover) with slight inflammation (different shape of nuclei, stainability, irregular contour of the nuclear border) (Papanicolaou stain, $\times 40$ ).

\section{Discussion}

In Romania there is a large number of institutionalized children and a lack of scientific information regarding the consequences of this policy on oral health. Moreover, central Romania is multicultural and different minorities among which Hungarians and local Roma population are the most numerous. This allows a better assessment of more variables, in the effort to find possible risk factors for the development of OSH. The last few decades have been marked by increased scientific information on self-harm behavior, which could be the result of the interest of specialists or better diagnostic methods. Although considered pathological, it was reported that a large number of individuals have experienced a selfharm behavior at least once or even for a period of time in their life [18,19]. To be considered self-injury, a lesion must have the following characteristics: repetitive, socially unacceptable and to cause mild/moderate tissue damage [20]. Therefore, these lesions are usually hidden, the exact prevalence in the world is unknown and is believed to be underestimated [21]. Recent studies reported different percentages depending on the group of population analyzed, ranging from $4 \%$ in adults, $17-38 \%$ in students, $7.7-22.8 \%$ in institutionalized 
patients with mental disorders to $69 \%$ in high-risk young people (victims of sexual abuse or drug users) [22-25]. NSSI is a relatively common and insidious pervasive, often concealed habit that may start in childhood and increase in adolescence and young adulthood. Adolescent girls seem more vulnerable and the key components of NSSI behavior are represented by negative emotion and saturnine self-derogation [26,27].

According to data from literature, ethnicity might have an influence on self-harm behavior [28]. This was confirmed by the results of our study, as the group of local Roma showed statistically significant higher odds of developing OSH lesions compared to Romanians. The influence of ethnicity upon self-injury behavior was further confirmed by Toth et al. [29] who found that Roma population from Hungary is characterized by higher odds of developing suicidal behavior compared to non-Roma ethnics. The authors mention that studies from the UK and Hungary partially explain these tendencies by the high incidence of anxiety, depression and hostility from the majority population. For the Roma population in particular, the family concept has an important social value and, therefore, the lack of cohesion with relatives experienced by institutionalized children could be a strong negative factor for the development of anxiety and depression. These problems aggravate during adolescence and adulthood as a result of poverty, low educational level, and unemployment.

In a meta-analysis, published by Lang and Yao in 2018 [30], the estimated prevalence of NSSI in Chinese middle-school students was $22.37 \%$, considered relatively high, females being more susceptible to this behavior ( $21.9 \%$ compared to a prevalence of $20.6 \%$ reported in male students). The results of our study are in accordance with this data, as out of the OSH overall prevalence of $18.1 \%, 13.79 \%$ were attributed to female participants and only $4.31 \%$ to male participants.

$\mathrm{OSH}$ is not a frequently encountered phenomenon in the daily clinical practice, but it can represent the first manifestation of a psychiatric disorder. AlSadhan et al. [31] found a higher prevalence of OSH among institutionalized children from Saudi Arabia, including gingival or mucosal lesions, cheek and lip biting. Traumatic lesions of the lips, accompanied by loss of tissue were recognized by many authors as the most frequent injuries of the oral mucosa. [32] This was explained by the proximity of incisors and canines, teeth with sharp cusps and incisal margins. In our study, the distribution of injuries is in accordance with scientific data, as the oral commissure and lips were affected in $35.48 \%$ and $32.26 \%$ cases, respectively, while the tongue was injured only in $3.23 \%$ cases. The frequent lesion of the oral commissure could be explained by the presence of caliculus angularis, a small projection of keratinized mucosa, easily injured between upper and lower canine, associated with a decreased level of pain.

Based on the literature, children who self-harm claim to have little to no pain while they are hurting themselves but they feel tension and anger towards themselves or others. This was observed also by our investigators, as none of the children who presented with OSH complained about pain during examination. A drawback of our study is that during the oral examination no psychological assessment was performed and, therefore, the tension or anger could not be quantified. It is estimated that the incidence of habitual self-injurers is nearly $1 \%$ of the population with a higher proportion of females than males, the typical onset of self-harming acts is usually at puberty. This behavior lasts 5-10 years but it can persist much longer without the proper treatment [33,34]. Institutionalized children show an increased prevalence of oral habits and OSH, which indicate emotional stress. Moreover, foster caregivers frequently lack information on these subjects and are unable to provide the proper support for these children [31].

In a study from 2015, Tortorici et al. [35] reported that oral soft tissue injuries had an incidence estimated at $2.5 \%$ in the Caucasian population. In our study group, a chronic evolution was suspected in 6 cases with OSH (5.17\%) and these were further investigated using exfoliative cytology, the results confirming the benign evolution, with mild inflammation. The bite of the lips and buccal mucosa can destroy the superficial epithelium and if this parafunction has a chronic evolution, it can cause keratinized shreds or erosive and 
desquamative areas. These lesions can be easily identified by clinical inspection and are often related to psychologically tense persons [36]. However, in some cases, the lesions were mistaken for serious medical conditions and biopsies were required in order to rule out a malignancy. Therefore, it is important to perform a thorough clinical examination and to interpret the laboratory tests clearly [37].

\subsection{Clinical Relevance}

Identification of NSSI in the early stages is of utmost importance as scientific data confirm that up to $70 \%$ of these persons experienced also suicidal attempts [33]. Data from literature suggests that early age at which children engage in NSSI represents a risk factor for more episodes of NSSI during the lifetime with increased severity [17]. As self-injuries are conducted mainly in secret and may not be clearly visible, the periodic oral examination of these children might be useful in early diagnosis. Although minor OSH does not lead to a serious loss of tissue, it may affect oral health in the long run, with important social and emotional implications. Our results raise the question regarding efficient preventive measures, such as better training of caregivers and policies focusing on the psychosocial well-being of institutionalized children. Measures aiming to enhance subjective happiness and satisfaction with life at any age might decrease the prevalence of NSSI among institutionalized children [17].

\subsection{Strengths and Limitations}

According to our knowledge there were no studies addressing self-harm behavior of oral soft tissues in children from central Romania. However, our study encountered several limitations: the small sample size and cross-sectional design, which allowed a rapid and cost-effective evaluation of the prevalence of $\mathrm{OSH}$, but is unable to provide a clear association between investigated variables. Therefore, longitudinal studies on the general population are required for a better understanding of these emotional disorders. Moreover, cognitive assessment of these children would have been useful in order to adjust confounding factors.

Author Contributions: Conceptualization, A.M.S. and M.M.; methodology, O.E.S.; software, A.M.P.; validation, A.M.S. and M.M.; formal analysis, M.M.; investigation, O.E.S. and R.E.V.; data curation, O.E.S. and R.E.V.; writing—original draft preparation, A.M.S., O.E.S., R.E.V. and A.M.P.; writingreview and editing, M.M.; supervision, A.M.P. and M.M. All authors have read and agreed to the published version of the manuscript.

Funding: This research received no external funding.

Institutional Review Board Statement: The study was conducted according to the guidelines of the Declaration of Helsinki, and approved by the Ethics Committee of the George Emil Palade University of Medicine, Pharmacy, Science, and Technology of Târgu Mureș (protocol code 520/21.11.2019).

Informed Consent Statement: Informed consent was obtained from all subjects involved in the study.

Data Availability Statement: The data presented in this study are available on request from the corresponding author. The data are not publicly available due to privacy restrictions.

Conflicts of Interest: The authors declare no conflict of interest.

\section{References}

1. Klonsky, E.D.; Muehlenkamp, J.J. Self-injury: A research review for the practitioner. J. Clin. Psychol. 2007, 63, 1045-1056. [CrossRef] [PubMed]

2. Walsh, B. Clinical assessment of self-injury: A practical guide. J. Clin. Psychol. 2007, 63, 1057-1068. [CrossRef]

3. Greydanus, D.E.; Shek, D. Deliberate self-harm and suicide in adolescents. Keio J. Med. 2009, 58, 144-151. [CrossRef]

4. Skegg, K. Self-harm. Lancet 2005, 366, 1471-1483. [CrossRef]

5. Rosenthal, E. A Mandate to End Placement of Children in Institutions and Orphanages: The Duty of Governments and Donors to Prevent Segregation and Torture (16 February 2017). Prot. Child. Torture Deten. Glob. Solut. Glob. Probl. 2017. Available online: https://ssrn.com/abstract=3271306 (accessed on 12 November 2020).

6. Dozier, M.; Zeanah, C.H.; Wallin, A.R.; Shauffer, C. Institutional Care for Young Children: Review of Literature and Policy Implications. Soc. Issues Policy Rev. 2012, 6, 1-25. [CrossRef] 
7. Nsabimana, E.; Rutembesa, E.; Wilhelm, P.; Martin-Soelch, C. Effects of Institutionalization and Parental Living Status on Children's Self-Esteem, and Externalizing and Internalizing Problems in Rwanda. Front. Psychiatry 2019, 10, 442. [CrossRef]

8. Vajani, M.; Annest, J.L.; Crosby, A.E.; Alexander, J.D.; Millet, L.M. Nonfatal and fatal self-harm injuries among children aged 10-14 years-United States and Oregon, 2001-2003. Suicide Life Threat. Behav. 2007, 37, 493-506. [CrossRef]

9. Limeres, J.; Feijoo, J.F.; Baluja, F.; Seoane, J.M.; Diniz, M.; Diz, P. Oral self-injury: An update. Dent. Traumatol. 2013, 29, 8-14. [CrossRef]

10. Johnson, D.E.; Tang, A.; Almas, A.N.; Degnan, K.A.; McLaughlin, K.A.; Nelson, C.A.; Fox, N.A.; CZeanah, C.H.; Drury, S.S. Caregiving Disruptions Affect Growth and Pubertal Development in Early Adolescence in Institutionalized and Fostered Romanian Children: A Randomized Clinical Trial. J. Pediatr. 2018, 203, 345-353.e3. [CrossRef]

11. Sonuga-Barke, E.J.S.; Kennedy, M.; Kumsta, R.; Knights, N.; Golm, D.; Rutter, M.; Maughan, B.; Schlotz, W.; Kreppner, J. Child-to-adult neurodevelopmental and mental health trajectories after early life deprivation: The young adult follow-up of the longitudinal English and Romanian Adoptees study. Lancet 2017, 389, 1539-1548. [CrossRef]

12. Dobrova-Krol, N.A.; van Ijzendoorn, M.H.; Bakermans-Kranenburg, M.J.; Cyr, C.; Juffer, F. Physical growth delays and stress dysregulation in stunted and non-stunted Ukrainian institution-reared children. Infant Behav. Dev. 2008, 31, 539-553. [CrossRef] [PubMed]

13. Warner, H.A.; McCall, R.B.; Groark, C.J.; Kim, K.H.; Muhamedrahimov, R.J.; Palmov, O.I.; Nikiforova, N.V. Caregiver-child interaction, caregiver transitions, and group size as mediators between intervention condition and attachment and physical growth outcomes in institutionalized children. Infant Ment. Health J. 2017, 38, 645-657. [CrossRef] [PubMed]

14. Flemming, M.; Aronson, L. Child Maltreatment and Non-Suicidal Self-Injury. Information Brief Series, Cornell Research Program on Self-Injury and Recovery. Cornell University Ithaca, NY. 2016. Available online: http://www.selfinjury.bctr.cornell.edu/ perch/resources/the-relationship-between-child-maltreatment-and-non-suicidal-self-injuryfinal.pdf (accessed on 20 August 2020).

15. DiPierro, R.; Samo, I.; Perego, S.; Galucci, M.; Madeddu, F. Adolescent non-suicidal self-injury: The effects of personality traits, family relationship and maltreatment on the presence and severity of behaviours. Eur. Child Adolesc. Psychiatry 2012, 21, 511-520. [CrossRef]

16. Lang, C.M.; Sharma-Patel, K. The relation between childhood maltreatment and self-injury: A review of the literature on conceptualization and intervention. Trauma Violence Abuse 2011, 12, 23-37. [CrossRef]

17. Muehlenkamp, J.J.; Xhunga, N.; Brausch, A.M. Self-injury Age of Onset: A Risk Factor for NSSI Severity and Suicidal Behavior. Arch. Suicide Res. 2019, 23, 551-563. [CrossRef]

18. Buresova, I. Self-Harm classification system development: Theoretical study. Rev. Soc. Sci. 2016, 1, 3-20. [CrossRef]

19. Madge, N.; Hewitt, A.; Hawton, K.; De Wilde, E.J.; Corcoran, P.; Fekete, S.; van Heeringan, K.; DeLeo, D.; Ystgaard, M. Deliberate self-harm within an international community sample of young people: Comparative findings from the Child \& Adolescent Self-harm in Europe (CASE) Study. J. Child Psychol. Psychiatry 2008, 49, 667-677. [CrossRef]

20. Cannavale, R.; Itro, A.; Campisi, G.; Compilato, D.; Collella, G. Oral self-injuries: Clinical findings in a series of 19 patients. Med. Oral Pathol. Oral Cir. Bucal 2015, 20, e123. [CrossRef]

21. Klonsky, E.D. Non-suicidal self-injury in United States adults: Prevalence, sociodemographics, topography and functions. Psychol. Med. 2011, 41, 1981-1986. [CrossRef]

22. Gratz, K.L.; Conrad, S.D.; Roemer, L. Risk factors for deliberate self-harm among college students. Am. J. Orthopsychiatry 2002, 72, 128-140. [CrossRef]

23. Withlock, J.; Eckenrode, J.; Silverman, D. Self-injurious behaviors in a college population. Pediatrics 2006, 117, 1939-1948. [CrossRef]

24. Lloyd-Richardson, E.E.; Perrine, N.; Dierker, L.; Kelley, M.L. Characteristics and functions of non-suicidal self-injury in a community sample of adolescents. Psychol. Med. 2007, 37, 1183-1192. [CrossRef] [PubMed]

25. Wilkinson, B. Current trends in remediating adolescent self-injury: An integrative review. J. Sch. Nurs. 2011, 27, 120-128. [CrossRef] [PubMed]

26. Yates, T.M.; Carlson, E.A.; Egeland, B. A prospective study of child maltreatment and self-injurious behavior in a community sample. Dev. Psychopathol. 2008, 20, 651-671. [CrossRef] [PubMed]

27. Brunner, R.; Parzer, P.; Haffner, J. Prevalence and psychological correlates of occasional and deliberate self-harm in adolescents. Arch. Pediatr. Adolesc. Med. 2007, 161, 641-649. [CrossRef] [PubMed]

28. Portzky, G.; De Wilde, E.J.; van Heeringen, K. Deliberate self-harm in young people: Differences in prevalence and risk factors between the Netherlands and Belgium. Eur. Child Adolesc. Psychiatry 2008, 17, 179-186. [CrossRef]

29. Tóth, M.D.; Ádám, S.; Zonda, T.; Birkás, E.; Purebl, G. Risk factors for multiple suicide attempts among Roma in Hungary. Transcult. Psychiatry 2018, 55, 55-72. [CrossRef]

30. Lang, J.; Yao, Y. Prevalence of nonsuicidal self-injury in Chinese middle school and high school students. A meta-analysis. Medicine 2018, 97, e12916. [CrossRef]

31. AlSadhan, S.A.; Al-Jobair, A.M. Oral habits, dental trauma, and occlusal characteristics among 4- to 12-year-old institutionalized orphan children in Riyadh, Saudi Arabia. Spec. Care Dent. 2017, 37, 10-18. [CrossRef]

32. Millogo, M.; Ouedraogo, R.W.L.; Ily, V.; Konsem, T.; Ouedraogo, D. Labial lesions by human bite. J. Oral Med. Oral Surg. 2018, 24, 153-156. [CrossRef] 
33. Kostic, J.; Zikic, O.; Stankovic, M.; Nikolic, G. Nonsuicidal self-injury among adolescents in south-east Serbia. Int. J. Pediatr. Adolesc. Med. 2019, 6, 131-134. [CrossRef] [PubMed]

34. Tang, J.; Yang, W.; Ahmed, N.I.; Ma, Y.; Liu, H.Y.; Wang, J.J.; Wang, P.X.; Du, Y.K.; Yu, Y.Z. Stressful Life Events as a Predictor for Nonsuicidal Self-Injury in Southern Chinese Adolescence. A Cross-Sectional Study. Medicine 2016, 95, e2637. [CrossRef]

35. Tortorici, S.; Corrao, S.; Natoli, G.; Difalco, P. Prevalence and distribution of oral mucosal non-malignant lesions in the western Sicilian population. Minerva Stomatol. 2016, 65, 191-206. [PubMed]

36. Hailegiorgis, M.T.; Berheto, T.M.; Sibamo, E.L.; Asseffa, N.A.; Tesfa, G.; Birhanu, F. Psychological wellbeing of children at public primary schools in Jimma town: An orphan and non-orphan comparative study. PLoS ONE 2018, 13, e0195377. [CrossRef]

37. Monea, M.; Olah, P.; Comaneanu, R.M.; Hancu, V.; Ormenisan, A. The Role of Toluidine Blue as a Visual Diagnostic Method in Oral Premalignant Lesions. Rev. Chim. 2016, 67, 1370-1372. 